\title{
Methylmercury Determination In Sub-Ppb Level By Cold Vapor Analysis: Facts, Mechanisms And Optimization
}

\author{
Evgenios Kokkinos * and Anastasios Zouboulis \\ Department of Chemistry, Aristotle University of Thessaloniki, Greece \\ * Correspondence: evgenios@chem.auth.gr
}

\begin{abstract}
Recent reports, according to international organizations, on the highly toxic presence of methyl-mercury (MeHg) in the environment, classify it among the major/priority environmental pollutants. Understanding the need to find new, but also safe, sources of usable water and to monitor the current ones, regarding water quality, the aim of this study is to investigate the determination of $\mathrm{MeHg}$ by the application of cold vapor analysis, providing useful facts, considering the method's optimization, in order to be adopted also from other researchers. During the cold vapor analysis organic or/and inorganic mercury atomization takes place chemically by the addition of an appropriate reducing agent. The most known relevant agent is $\mathrm{SnCl}_{2}$, which however is able to reduce only the inorganic $\mathrm{Hg}$. Instead, $\mathrm{NaBH}_{4}$ is capable to reduce both $\mathrm{Hg}$ forms, but a pre-treatment of the sample is required, namely the addition of $\mathrm{KMnO}_{4}$. Therefore, in this work, the reagents' concentration was studied, and their role was clarified in every step of the proposed method analysis. According to the results, the addition of at least $0.0005 \% \mathrm{w} / \mathrm{v} \mathrm{KMnO}_{4}$ and $0.005 \% \mathrm{w} / \mathrm{v} \mathrm{NaBH} 4$ is needed in the aquatic sample for a reliable MeHg measurement. In fact, the formed $\mathrm{MnO}_{2}$, that produced by the reduction of residual $\mathrm{KMnO}_{4}$ from $\mathrm{NaBH}_{4}$, was found to catalyze the $\mathrm{MeHg}$ atomization reaction.
\end{abstract}

Keywords: methyl-mercury; cold vapor analysis; water quality; water monitoring;

\section{Introduction}

According to European Commission, mercury is included in the high priority pollutants list, regarding water policy [1]. Mercury is released in environment mainly as its inorganic ( $\mathrm{IHg}$ ), or elemental form, through anthropogenic emissions. Organic mercury $(\mathrm{OHg})$, mainly as the methyl-mercury (MeHg) form, is created through biotic mechanisms (bacterial actions) under anoxic conditions, when the inorganic and elemental $\mathrm{Hg}$ species are entering water resources and sea water. $\mathrm{MeHg}$ is the most toxic substance among the other mercury compounds, due to its higher ability for bioaccumulation. In other words, it can accumulate in the living tissues and therefore, increases gradually its concentration in the food chain, e.g starting from the micro-organisms, such as plankton, going to small fishes and finally, ending to the contamination of humans [2].

As a result of water pollution, through the appearance of toxic pollutants, such as $\mathrm{MeHg}$, the need to monitor the quality of water, used to meet the various human needs, becomes mandatory [3]. Especially, when taking into account the water scarcity in many regions worldwide, the aforementioned need becomes even greater, in an effort to explore new/alternative water resources for potential re/use. Regarding mercury, its hazardousness is also reflected in the lowest drinking water regulation limit, as set by international organizations, among the other toxic metals, which is at $1 \mu \mathrm{g} / \mathrm{L}$ of total $\mathrm{Hg}$. However, as in the aqueous phase the dominant form of mercury is the methylated one, precise analytical methods should be developed respectively, being able to determine the specific pollutant species at the sub-ppb levels. Cold vapor analysis is a well known technology that can fulfill this criterium, but according to the relevant literature, there is no a commonly acceptable unified experimental procedure and therefore, further investigation is still required $[4,5]$. 
The aim of this study is to evaluate the two major reagents, used in cold vapor analysis for mercury atomization, namely $\mathrm{SnCl}_{2}$ and $\mathrm{NaBH}_{4}$ and furthermore, to investigate the possibility of an appropriate pre-treatment step in order to optimize the $\mathrm{MeHg}$ determination, namely the addition of $\mathrm{KMnO}_{4}$. Moreover, the initial experimental pollutant's concentration was in the range of $0-10 \mu \mathrm{g} / \mathrm{L}$, i.e. close to the realistic environmental pollution cases, while as matrix a natural-like water was applied, prepared according to National Sanitation Foundation, in an effort to replicate the actual field conditions during the evaluation of the analytical method.

\section{Materials and Methods}

\subsection{Reagents}

Mercury working standard solutions were prepared for both species, i.e. inorganic and organic. Regarding $\mathrm{IHg}$, a $1000 \mathrm{mg} \mathrm{IHg} / \mathrm{L}$ standard solution (prepared mainly for atomic adsorption spectroscopy) was used. Instead, a $50 \mathrm{mg} \mathrm{OHg} / \mathrm{L}$ working solution was prepared by dissolving 31.29 $\mathrm{mg}$ of reagent grade $\mathrm{MeHgCl}$ in $50 \mathrm{~mL} \mathrm{HCl} 6 \mathrm{~N}$ and diluted to $0.5 \mathrm{~L}$ with distilled water. Similarly, freshly made working standard solutions were prepared by dissolving reagent grades of $\mathrm{KMnO}_{4}$ $(0.2 \% \mathrm{w} / \mathrm{v}), \mathrm{NaBH}_{4}(1 \% \mathrm{w} / \mathrm{v})$ and $\mathrm{SnCl}_{2}(1 \% \mathrm{w} / \mathrm{v})$ in $0.5 \mathrm{~N} \mathrm{HNO}_{3}, 0.1 \mathrm{~N} \mathrm{NaOH}$ and concentrated $\mathrm{HCl}$ prior to distilled water dilution, respectivelly.

The NSF water was prepared by diluting $252 \mathrm{mg} \mathrm{NaHCO}$, $12.14 \mathrm{mg} \mathrm{NaNO}$, $0.178 \mathrm{mg}$ $\mathrm{NaH}_{2} \mathrm{PO}_{4} \cdot \mathrm{H}_{2} \mathrm{O}, 2.21 \mathrm{mg} \mathrm{NaF}, 70.6 \mathrm{mg} \mathrm{NaSiO} 3 \cdot 5 \mathrm{H}_{2} \mathrm{O}, 147 \mathrm{mg} \mathrm{CaCl} 2 \cdot 2 \mathrm{H}_{2} \mathrm{O}$, and $128.3 \mathrm{mg} \mathrm{MgSO} \cdot 7 \mathrm{H}_{2} \mathrm{O}$ in $1 \mathrm{~L}$ of distilled water [6].

\subsection{Mercury determination}

Mercury concentration was determined by using a Bacharach cold vapor mercury analyzer system (Coleman-Model 50B). In particular, $100 \mathrm{~mL}$ of the sample, pre-treated or not, is placed in a ground-necked flask and the reducing agent was added $\left(\mathrm{NaBH}_{4}\right.$ or $\left.\mathrm{SnCl}_{2}\right)$. A nozzle, also grounded, was fitted directly to the flask, which allows the formed metal hydride to be trapped in the now closed flask-instrument system. Within 2 min the concentration has stabilized inside the instrument and the percentage of transmittance was recorded through an ultraviolet lamp (wavelength 253.7 $\mathrm{nm}$ ). The limit of detection (LOD), according to the manufacturer, is $0.2 \mu \mathrm{g} \mathrm{Hg} / \mathrm{L}$.

\section{Results and Discussion}

\subsection{Comparison of reagents}

The first step to confirm the functionality/applicability of proposed method is to highlight the existing problem and to evaluate the appropriate sample's pretreatment. Indeed, by applying the two common reducing agents for $\mathrm{Hg}$ atomization (i.e. $\mathrm{NaBH}_{4}$ or $\mathrm{SnCl}_{2}$ ) during the cold vapor analysis, it was proved that only $\mathrm{NaBH}_{4}$ is capable for the efficient $\mathrm{MeHg}$ atomization [7]. According to Fig. 1, presenting the corresponding calibration carves, the addition of $\mathrm{SnCl}_{2}(0.05 \% \mathrm{w} / \mathrm{v})$ can oxidize sufficiently the IHg form $\left(R^{2}=0.997\right)$. On the other hand, no change in the transmittance value was observed, when $\mathrm{SnCl}_{2}$ used for the $\mathrm{MeHg}$ oxidation, and so the corresponding data are not presented. Instead, when the $\mathrm{NaBH}_{4}$ reagent $(0.05 \% \mathrm{w} / \mathrm{v})$ was used, then the $\mathrm{MeHg}$ oxidized to its elemental mode, but not sufficiently enough. The corresponding calibration curve indicates that for $\mathrm{OHg}$ concentration above $5 \mu \mathrm{g} / \mathrm{L}$, this method yielded rather inaccurate transmittance values $\left(\mathrm{R}^{2}=0.954\right)$. In addition, by applying acidic conditions (using $\left.0.1 \mathrm{~N} \mathrm{HCl}\right)$ to this procedure, only slight variations in transmittance where obtained $\left(\mathrm{R}^{2}=0.935\right)$ [8].

In order to be developed a reliable methodology, it was considered as necessary the application of an appropriate pre-treatment step, i.e. before the addition of $\mathrm{NaBH}_{4}$ in the sample. For this purpose the reagent $\mathrm{KMnO}_{4}(0.0005 \% \mathrm{w} / \mathrm{v})$ was selected, due to its high oxidizing ability, which favors the conversion of $\mathrm{MeHg}$ to $\mathrm{Hg}^{2+}$ and hence, the metal's atomization rate is expected to be increased [9]. According to the respective results, the combination of $\mathrm{NaBH}_{4}$ with the pre-treatment step can minimize the value of transmittance for the highest examined MeHg concentration (10 
$\mu \mathrm{g} / \mathrm{L})$ and yields a reliable calibration curve $\left(\mathrm{R}^{2}=0.998\right)$. To investigate the effect of $\mathrm{KMnO}_{4}$ on $\mathrm{MeHg}$, the calibration curve with the addition of $\mathrm{SnCl}_{2}$ was also conducted. The corresponding data verified the $\mathrm{MeHg}$ conversion to its $\mathrm{Hg}^{2+}$ form, but the respective efficiency of this transformation is rather limited and linear $\left(R^{2}=0.997\right)$, meaning that only a part of the initial concentration was modified to the non-methylated mode during the pre-treatment step. The proved reliability of the previous method was mainly attributed to a $2^{\text {nd }}$ mechanism, which co-exists during the determination; i.e. the excess of $\mathrm{KMnO}_{4}$ reacted with $\mathrm{NaBH}_{4}$, resulting in the secondary production of $\mathrm{MnO}_{2}$, which was also confirmed by the discoloration of sample. As a result, the produced $\mathrm{MnO}_{2}$ behaved as catalyst in the atomization reaction of $\mathrm{MeHg}$ [10].

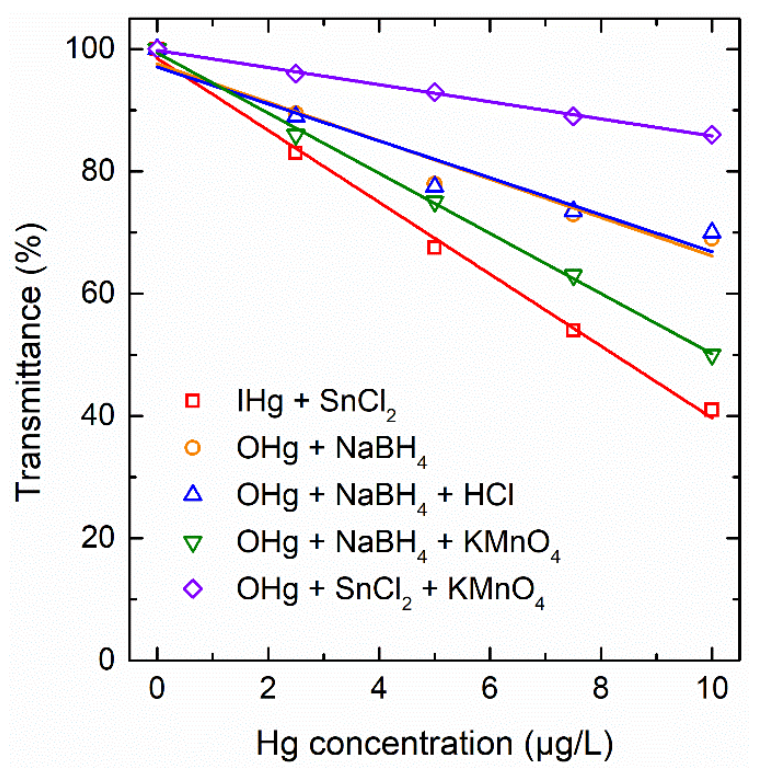

Figure 1. Calibration curves of $\mathrm{OHg}$ and $\mathrm{IHg}$ by appling various reagents and pre-treatment steps.

\subsection{Reliability of analytical procedure}

Since the use of reagents $\mathrm{KMnO}_{4}$ and $\mathrm{NaBH}_{4}$ was shown to be capable of providing a reliable calibration curve, then the method was also tested in terms of providing quantitative data, when possible interferences are occurring [7]. For this purpose, the standar addition method was applied, where at each sample a constant concentration of $\mathrm{MeHg}$ equal to $2.5 \mu \mathrm{g} / \mathrm{L}$ is added, which is considered as a theoretical value, intended to be co-determined/co-verified, as well as a variable concentration of $\mathrm{IHg}$ in the range between 0 to $7.5 \mu \mathrm{g} / \mathrm{L}$. By extending the resulting curve, it is possible to determine the theoretical $\mathrm{MeHg}$ concentration, which will be equal to the point of intersection at the $100 \%$ permeability value. According to Fig. 2, the respective data provided a high linearity curve $\left(\mathrm{R}^{2}=0.998\right)$, whereas the estimated concentration of $\mathrm{MeHg}$, through its intersection (red line), differs only slightly from the theoretical one (i.e. 2.58 insttead of $2.50 \mu \mathrm{g} / \mathrm{L}$ ); thus, proving the high reliability of the proposed method with $103 \%$ recovery, i.e. within the acceptable analytical limits.

Another interesting fact, resulting from the determinatiom of $\mathrm{OHg}$, $\mathrm{IHg}$ and mixed $\mathrm{OHg} / \mathrm{IHg}$ by $\mathrm{NaBH}_{4}$, was the different trasmittance values yielded for a constant concentration of total $\mathrm{Hg}$ (Fig. 1 and 2). These vairations were attributed to the formation of $\mathrm{CH}_{3} \mathrm{HgH}$, a methyl-mercury hydride volatilized among with $\mathrm{Hg}^{0}$ [5]. 


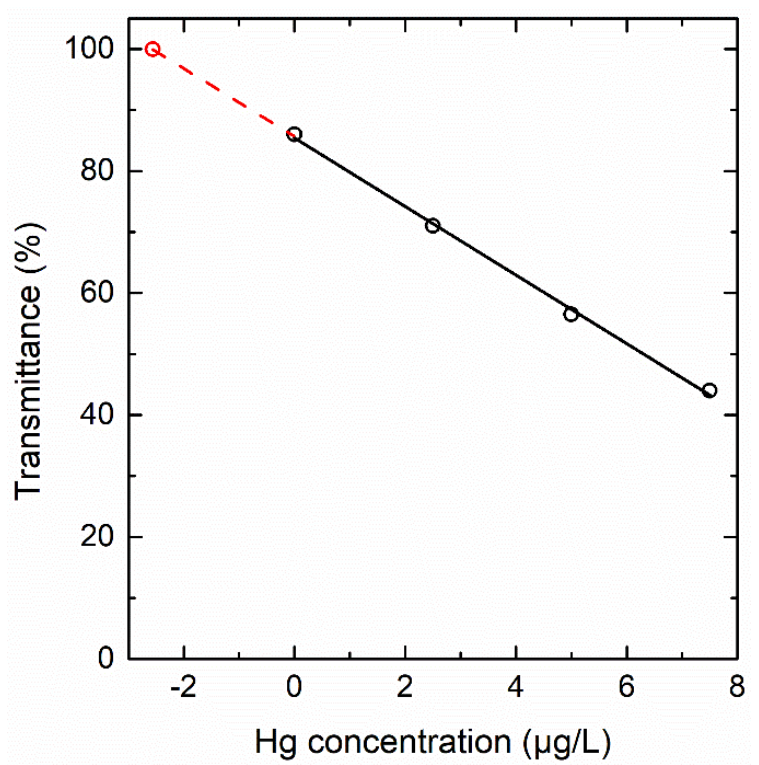

Figure 2. Determination of $2.5 \mu \mathrm{g} \mathrm{OHg} / \mathrm{L}$ by applying the standar addition method.

\subsection{Optimazation of analytical procedure}

The next step, regarding the optimization of applied method, was to investigate the effect of $\mathrm{KMnO}_{4}$ and $\mathrm{NaBH}_{4}$ concentrations, i.e. the two reagents used in the proposed $\mathrm{MeHg}$ determination by the cold vapor analysis, especially after proving that they can react with each other [9]. The initial $\mathrm{MeHg}$ concentration in each sample was $10 \mu \mathrm{g} \mathrm{OHg} / \mathrm{L}$, as the highest concentration of investigated range, while the matrix was the NSF water, as before. By keeping the $\mathrm{NaBH}_{4}$ content constant $(0.05 \%$ $\mathrm{w} / \mathrm{v}$ ) in the samples, it was concluded that the measured transmittance showed its lower value at $0.0005 \% \mathrm{w} / \mathrm{v} \mathrm{KMnO}_{4}$, while a further increase in its concentration caused no further changes (Fig. 3). Then, and keeping the $\mathrm{KMnO}_{4}$ content constant as previously determined, it was found that the optimum content of $\mathrm{NaBH}_{4}$ was $0.005 \% \mathrm{w} / \mathrm{v}$, i.e. an order of magnitude lower, than in the initial experiments.
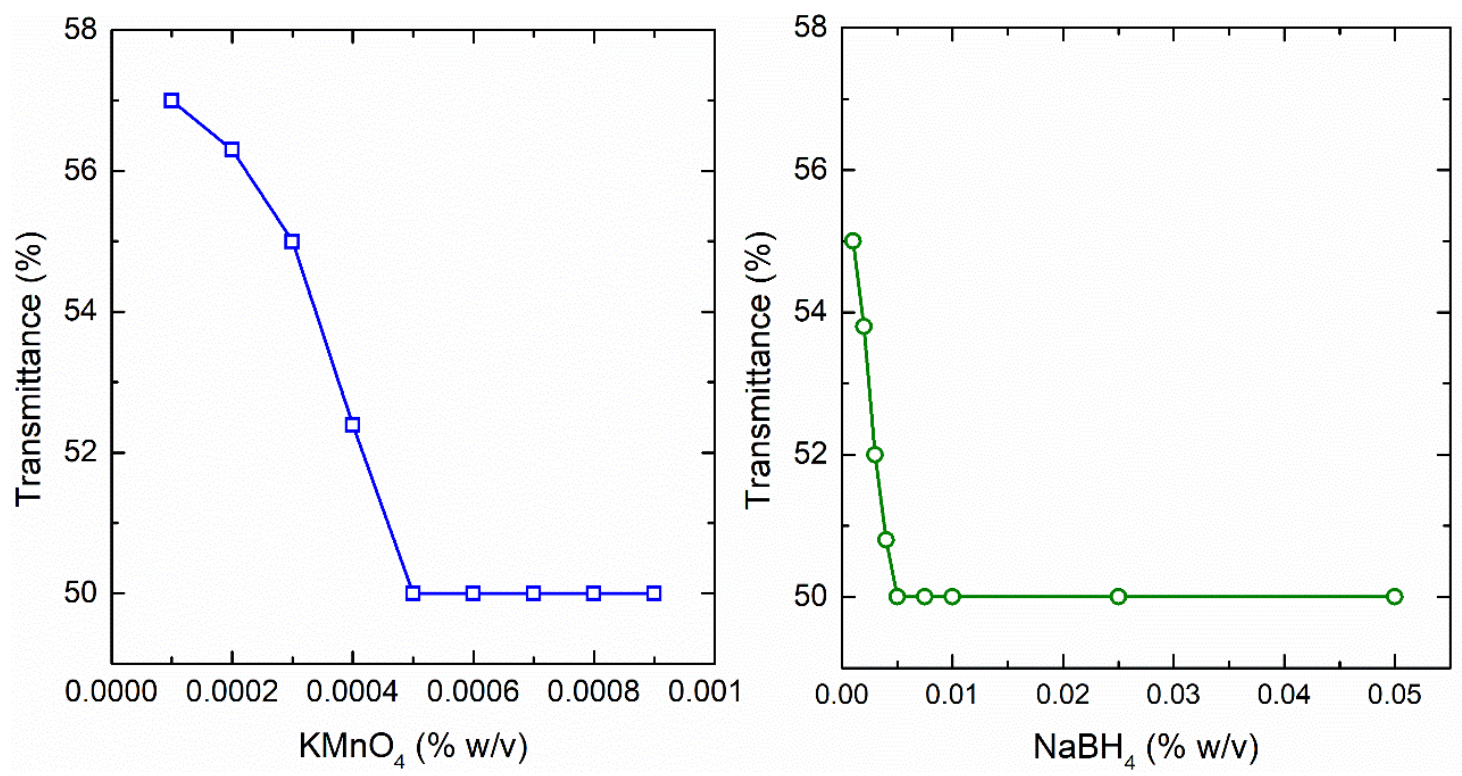

Figure 3. Effect of $\mathrm{KMnO}_{4}$ and $\mathrm{NaBH}_{4}$ concentration, considering the transmittance percentage of 10 $\mu \mathrm{g} \mathrm{OHg} / \mathrm{L}$.

\subsection{Interferences of the analytical procedure}


Since the addition of $\mathrm{KMnO}_{4} / \mathrm{NaBH}_{4}$ content was proved to be crucial and due to the oxidizing behavior of $\mathrm{KMnO}_{4}$, some interferences may occur. Initially, it should be clarified that none of the ions contained in NSF water, i.e. common ions usually existing in natural waters, had any effect in the results obtained by this method. This aspect was proved also by using distilled water as matrix/background for the analytical determination, without observing any variations in transmittance values [4]. Moreover, and in order to avoid any contamination of the samples, e.g. by the presence of possible impurities of mercury in the used reagents, it is preferable to apply the minimum optimized concentrations of reagents, while keeping constant their rate. Instead, interferences are expected, when the sample contains metals that may be oxidized by $\mathrm{KMnO}_{4}$, such as $\mathrm{Fe}$ [11]. In that case, the inhibitory agent must be firstly neutralized by the $\mathrm{KMnO}_{4}$ addition in order to obtain reliable results, and therefore, a different $\mathrm{KMnO}_{4} / \mathrm{NaBH}_{4}$ content should be defined.

\section{Conclusions}

In this study the determination of methyl-mercury by the application of cold vapor analysis was investigated and optimized in order to provide useful information, regarding the method's mechanism, and being able to be adopted by other researchers as well. A key factor is considered to be the addition of $\mathrm{KMnO}_{4}$ in a pre-treatment step, during which the $\mathrm{OHg}$ can be partially conversed to $\mathrm{Hg}^{2+}$, acting also as a $\mathrm{MnO}_{2}$ source, through its (secondary) reaction with $\mathrm{NaBH}_{4}$, which is behaving as catalyst during the measurement. This method proved to be reliable and without interferences, thus making it suitable for determining sub-ppb levels of $\mathrm{MeHg}$ in natural waters.

Acknowledgments: This research is co-financed by Greece and the European Union (European Social Fund- ESF) through the Operational Programme «Human Resources Development, Education and Lifelong Learning» in the context of the project "Reinforcement of Postdoctoral Researchers 2nd Cycle" (MIS-5033021), implemented by the State Scholarships Foundation (IKY).

Conflicts of Interest: The authors declare no conflict of interest. The founding sponsors had no role in the design of the study; in the collection, analyses, or interpretation of data; in the writing of the manuscript, and in the decision to publish the results.

\section{References}

1. European Commission Decision No. 2455/2001/EC of the European Parliament and of the Council establishing the list of priority substances in the field of water policy and amending Directive 2000/60/EC. Off. J. Eur. Union L 3312001.

2. EEA Mercury in Europe's environment. A priority for European and global action. Eur. Environ. Agency (EEA), Copenhagen 2018, https://doi.org/10.2800/558803.

3. UNEP/MAP 2017 Mediterranean Quality Status Report. Mediterranean Action Plan, Barcelona 2017, https://www.medqsr.org/sites/default/files/inline-files/2017MedQSR_Online_0.pdf.

4. Li, D.; Li, Y.; Wang, X. Study on the simultaneous reduction of methylmercury by $\mathrm{SnCl} 2$ when analyzing inorganic Hg in aqueous samples. J. Environ. Sci. (China) 2018. https://doi.org/10.1016/j.jes.2018.02.017

5. Park, C.J.; Do, H. Determination of inorganic and total mercury in marine biological samples by cold vapor generation inductively coupled plasma mass spectrometry after tetramethylammonium hydroxide digestion. J. Anal. At. Spectrom. 2008. https://doi.org/10.1039/B805307N

6. Kokkinos, E.; Simeonidis, K.; Zouboulis, A.; Mitrakas, M. Mercury removal from drinking water by single iron and binary iron-manganese oxyhydroxides. Desalin. Water Treat. 2015, 54, 2082-2090, https://doi.org/10.1080/19443994.2014.934105.

7. Krishna, M.V.B.; Karunasagar, D. Robust ultrasound assisted extraction approach using dilute TMAH solutions for the speciation of mercury in fish and plant materials by cold vapour atomic absorption spectrometry (CVAAS). Anal. Methods 2015, 7, 1997-2005, https://doi.org/10.1039/C4AY02114B.

8. Torres, D.P.; Vieira, M.A.; Ribeiro, A.S.; Curtius, A.J. Determination of inorganic and total mercury in biological samples treated with tetramethylammonium hydroxide by cold vapor atomic absorption spectrometry using different temperatures in the quartz cell. J. Anal. At. Spectrom. 2005, 20, 298-294, https://doi.org/10.1039/b416167j. 
9. Torres, D.P.; Borges, D.L.G.; Frescura, V.L.A.; Curtius, A.J. A simple and fast approach for the determination of inorganic and total mercury in aqueous slurries of biological samples using cold vapor atomic absorption spectrometry and in situ oxidation. J. Anal. At. Spectrom. 2009, 24, 1118-1122, https://doi.org/10.1039/b816622f.

10. Vlassopoulos, D.; Kanematsu, M.; Henry, E.A.; Goin, J.; Leven, A.; Glaser, D.; Brown, S.S.; O’Day, P.A. Manganese(iv) oxide amendments reduce methylmercury concentrations in sediment porewater. Environ. Sci. Process. Impacts 2018, 20, 1746-1760, https://doi.org/10.1039/C7EM00583K.

11. Suvarapu, L.N.; Baek, S.O. Recent Studies on the Speciation and Determination of Mercury in Different Environmental Matrices Using Various Analytical Techniques. Int. J. Anal. Chem. 2017, 3624015, https://doi.org/10.1155/2017/3624015.

(C) 2020 by the authors; licensee MDPI, Basel, Switzerland. This article is an open access article distributed under the terms and conditions of the Creative Commons by Attribution (CC-BY) license (http://creativecommons.org/licenses/by/4.0/). 